\title{
Guided wave propagation and scattering at composite delaminations
}

Hervin, F., Fromme, P.

F. Hervin, P. Fromme, "Guided wave propagation and scattering at composite delaminations," Proc. SPIE 11593, Health Monitoring of Structural and Biological Systems XV, 115930Q (22 March 2021); doi: 10.1117/12.2582363 


\title{
Guided Wave Propagation and Scattering at Composite Delaminations
}

\author{
F. Hervin and P. Fromme \\ Department of Mechanical Engineering, University College London, WC1E 7JE, UK
}

\begin{abstract}
Composite structures, consisting of highly anisotropic layers of polymer matrix reinforced with high strength carbon fibers, are widely used for aerospace applications due to their low weight and high strength. However, impact during aircraft operation can lead to barely visible and difficult to detect damage. Depending on impact severity, delaminations can occur that reduce the structural integrity and load carrying capacity. Efficient structural health monitoring (SHM) of composite panels can be achieved using guided ultrasonic waves propagating along the structure. Guided ultrasonic wave propagation and scattering at circular delaminations was modelled using full three-dimensional (3D) Finite Element (FE) simulations in ABAQUS. Individual ply layers were modelled using unidirectional composite material properties to accurately capture the anisotropy effects. The guided ultrasonic wave propagation and scattered field at an artificial delamination was measured using a noncontact laser interferometer and quantified. Good agreement between experiments and Finite Element predictions was found and the energy trapping on top of a shallow delamination was verified. The influence of delamination shape and depth was investigated from a FE parameter study. The sensitivity of guided waves for the detection of delaminations due to barely visible impact damage (BVID) in composite panels has been verified.
\end{abstract}

Keywords: Composite material, CFRP, Laminate, Lamb waves, Scattering, Delamination.

\section{INTRODUCTION}

Composite laminates are increasingly used in a range of industries to reduce the weight of components whilst maintaining mechanical performance. Composite multi-layer structures have high in-plane strength, but possess poor interlaminar strength and are therefore prone to impact damage [1]. When stressed by transversely concentrated loading, for example a bird strike or dropped tool, extensive damage can develop below the surface of the laminate, which is difficult to detect by visual inspection [2]. Reliable structural health monitoring (SHM) techniques are therefore required to locate and characterise damage. Delamination, i.e., cracking in the interfacial plane between two adjacent layers in a composite laminate, represents the most common and critical failure mode, potentially causing separation of the ply layers [3]. In polymer composites, in contrast to metals, delamination can take place under a relatively small impact load [1,4]. The subsequent application of external loads may cause delamination growth, resulting in significant strength reduction, and eventual catastrophic failure of the composite component [5]. Several non-destructive techniques have been used to monitor composite components, particularly radiographic [6,7] and ultrasonic methods [8].

Guided waves are widely used for damage detection in thin-walled structures, due to their ability to propagate over long distances, allowing rapid and efficient detection of defects [9]. Guided waves are dispersive ultrasonic waves characterized by several propagation modes. Due to increasing wave attenuation with frequency, especially for composite structures, the first antisymmetric $\left(\mathrm{A}_{0}\right)$ and first symmetric $\left(\mathrm{S}_{0}\right)$ modes at lower frequencies are often used for damage detection. Scattering and mode conversion at the damage location can be used for the detection and characterization of structural defects or material inhomogeneities [10]. Numerical simulations and experimental investigations have demonstrated the capacity for the detection of delaminations [11, 12]. The reflection of the incident symmetric mode $\left(\mathrm{S}_{0}\right)$ from a delamination is strongly dependent on the through thickness position of the disbond. If the shear stress at the delamination interface is zero, no wave reflection is obtained [9]. In contrast the $\mathrm{A}_{0}$ mode, a flexural mode at low frequencies, can detect delaminations at any depth [13]. The $A_{0}$ mode has shorter wavelengths (at the same excitation frequency) than the $S_{0}$ mode and so is more suitable for the detection of small damage in composites. When a guided wave mode interacts with a delamination, waves propagate in each of the sub-laminates. Multiple reflections and mode conversion to the $S_{0}$ mode may occur in the delaminated region [14]. Numerous studies have reported a significant increase in amplitude of the $A_{0}$ mode on top of the delamination, which could be exploited for damage detection [15]. The arrival times of the multiple reflections can be used to estimate the size of delaminations [14].

Health Monitoring of Structural and Biological Systems XV, edited by Paul Fromme,

Zhongqing Su, Proc. of SPIE Vol. 11593, 115930Q - (c) 2021 SPIE

CCC code: $0277-786 \mathrm{X} / 21 / \$ 21 \cdot$ doi: $10.1117 / 12.2582363$

Proc. of SPIE Vol. 11593 115930Q-1 
The scattering characteristics of the fundamental anti-symmetric mode at material and geometric discontinuities have been investigated numerically and experimentally. In general, the $\mathrm{A}_{0}$ scattering at a delamination in an anisotropic multi-layer plate is more complicated than the scattering at a defect in isotropic plates [16]. For quasi-isotropic composite laminates, the scattering directivity patterns are dominated by the fiber orientation of the outer laminae and are highly dependent on the ply layup of the laminate [17]. Scattered amplitudes and directivity distributions are influenced by the delamination size to wavelength ratio and the through-thickness location, as the forward scattered amplitude is dependent on the phase difference between the waves propagating in each sub-laminate [18]. For a circular delamination, the amplitudes show a large forward scattered wave relative to the reflected pulse, as highlighted by numerical simulations [19]. Numerical studies have demonstrated that the maximum amplitude in the scattered field increases with delamination size [20]. The forward scattered field becomes dominant with increased delamination size. These considerations can be employed for the characterization of delamination damage in SHM applications. In quasi-isotropic composite laminates, the fiber steering effects in the outermost plies have a significant influence on the scattering pattern [21,10], which is in agreement with the results presented in [16].

Whilst there are several numerical studies focused on $\mathrm{A}_{0}$ mode scattering at delaminations in composite laminates, limited experimental studies have been performed. In this work a full 3D finite element model of a quasi-isotropic composite laminate containing a zero-volume ellipse shaped delamination is presented. The scattering of the $\mathrm{A}_{0}$ wave mode at a zerovolume ellipse shaped delamination is investigated. The model is validated against full field, noncontact laser measurements performed on a CFRP panel containing an artificial insert delamination [22]. The effect of delamination shape and depth is investigated from a numerical parameter study.

\section{EXPERIMENTAL MEASUREMENTS}

Experimental measurements were performed on a symmetric, quasi-isotropic graphite/epoxy laminate [23] with dimensions $600 \times 600 \times 1.6 \mathrm{~mm}^{3}$ and stacking sequence $[-45 /+45 / 90 / 0]_{\mathrm{s}}$. The mechanical properties of the single ply layer are provided in Table 1.

Table 1: Engineering constants for a single ply layer in the CFRP laminate. Moduli are given in GPa.

\begin{tabular}{cccccccccc}
\hline $\mathrm{E}_{1}$ & $\mathrm{E}_{2}$ & $\mathrm{E}_{3}$ & $\mathrm{G}_{12}$ & $\mathrm{G}_{13}$ & $\mathrm{G}_{23}$ & $v_{12}$ & $v_{13}$ & $v_{23}$ & $\rho\left[\mathrm{kgm}^{-3}\right]$ \\
\hline 175 & 6.90 & 6.90 & 4.18 & 4.18 & 2.35 & 0.25 & 0.25 & 0.46 & 1520 \\
\hline
\end{tabular}

A circular polytetrafluoroethylene (PTFE) film, $15 \mathrm{~mm}$ in diameter, was placed between the second and third ply $(0.4 \mathrm{~mm}$ depth) during the layup process. The position of the delamination was verified though an ultrasonic immersion C-Scan. Around the artificial delamination, a circular crown was identified where the plies are detached, giving an actual flaw size of approximately $20 \mathrm{~mm} \times 16 \mathrm{~mm}$ [24]. A schematic view showing the laminated panel is given in Fig. 1 .

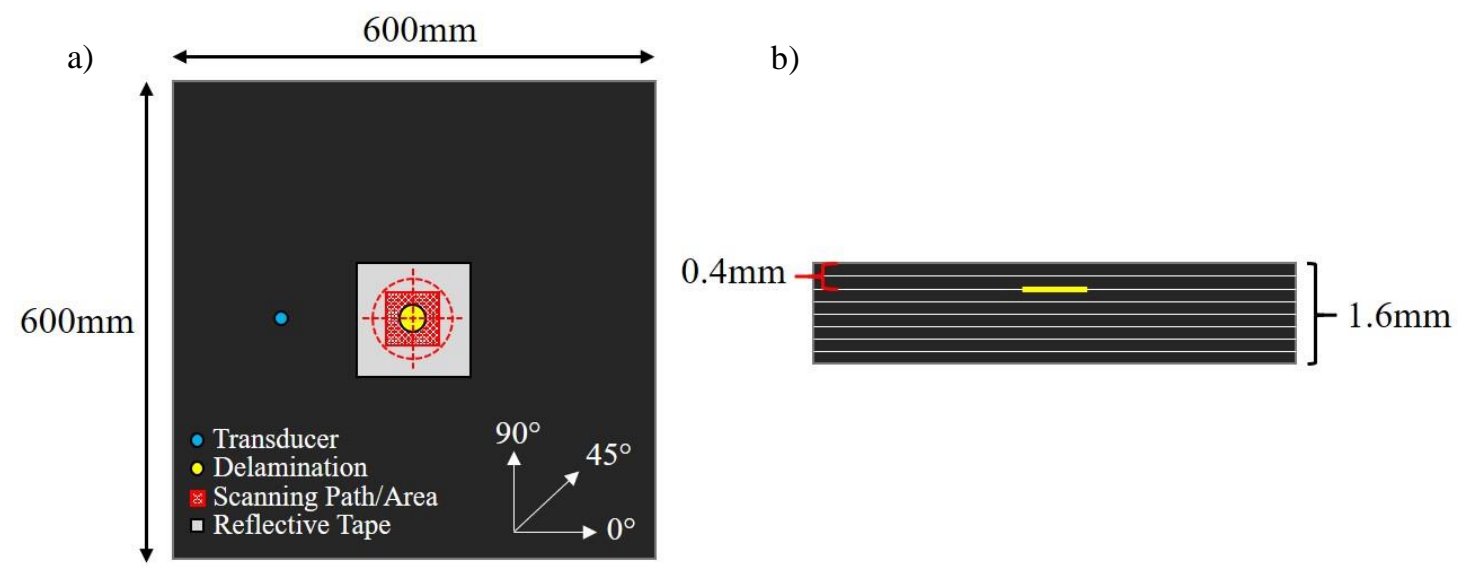

Figure 1: a) schematic of quasi-isotropic composite laminate (top view) with damage and PZT transducer marked. Red lines indicate scanning paths; b) schematic of damage location through plate thickness. 


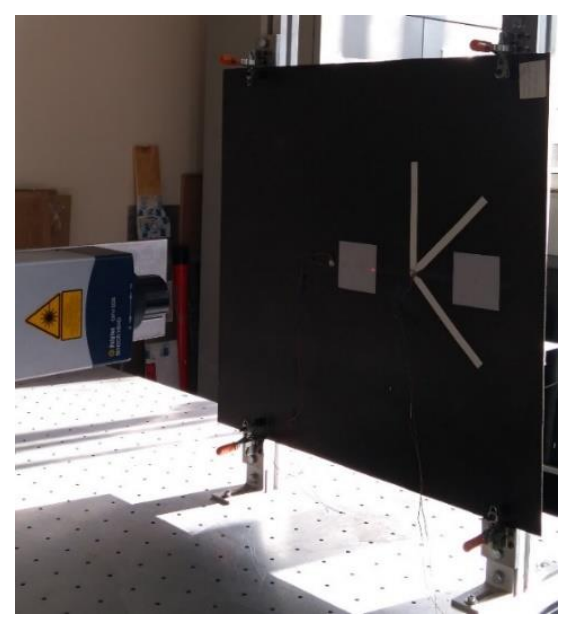

Figure 2: Experimental setup with laser head and composite specimen.

A photograph of the experimental setup is shown in Fig. 2. A piezoelectric transducer (lead zirconate titanate (PZT) disk, PI Ceramic PIC-255, diameter $10 \mathrm{~mm}$, thickness $0.25 \mathrm{~mm}$ ) was bonded by cyanoacrylate glue to the surface of the composite plate $100 \mathrm{~mm}$ from the center of the delamination location and was used to generate the $\mathrm{A}_{0}$ guided wave mode at $50 \mathrm{kHz}$. The excitation signal was a 5-cycle sine wave, modulated by a Hanning window and was generated using a programmable function generator (Agilent 33220A). The excitation signal was amplified to $50 \mathrm{Vpp}$ (Krohn-Hite $7602 \mathrm{M}$ wideband amplifier) and applied to the transducer. A laser vibrometer (Polytec sensor head OFV-505, OFV-5000 vibrometer controller) attached to a scanning rig was used to measure the velocity of the out-of-plane displacement of the plate surface. The laser head was moved parallel to the sample both horizontally and vertically. Retroreflective tape was applied to the plate to improve the laser beam reflection and thus signal-to-noise ratio. The time signals were filtered using a $25-75 \mathrm{kHz}$ band-pass filter and recorded and averaged 20 times using a digital storage oscilloscope. Time trace signals were saved to a PC for further analysis in MATLAB.

Three different scans were performed on the sample, shown in Fig. 1a. A square area $40 \mathrm{~mm}$ x $40 \mathrm{~mm}$ centered on the delamination was scanned in $1 \mathrm{~mm}$ steps. A horizontal line scan passing through the center of the delamination, $60 \mathrm{~mm}$ in length, was performed in steps of $1 \mathrm{~mm}$. A circular scan centered on the delamination with radius $30 \mathrm{~mm}$ was performed in steps of $2^{\circ}$. The total energy of the signal was obtained by summing the square of the amplitude for each point in the time trace. Amplitudes were normalized using an estimate of the incident wave amplitude as a reference value. The energy of the incident wave was estimated by calculating the mean of the energy values in front and behind the delamination from the horizontal line scan.

\section{FINITE ELEMENT SIMULATIONS}

A full 3D finite element model was developed with dimensions $600 \mathrm{~mm}$ x $600 \mathrm{~mm}$ x $1.2 \mathrm{~mm}$ to match the physical sample. Each ply layer was modelled with the material properties of a unidirectional composite laminate, as given in Table 1 . An element size of $0.5 \mathrm{~mm} \times 0.5 \mathrm{~mm} \times 0.2 \mathrm{~mm}$ was selected, which results in 1 element thickness per ply layer. Solid brick elements with reduced integration (C3D8R) were selected to provide a uniform mesh throughout the model. The model parameters were entered into a MATLAB program, which was used to generate an input file, which could then be imported into ABAQUS/Explicit to perform the analysis. The stable time increment was $50 \mathrm{~ns}$ and the simulation time was $0.3 \mathrm{~ms}$. Propagation of the $\mathrm{A}_{0}$ mode was modelled by applying an out-of-plane force to a single node $100 \mathrm{~mm}$ from the center of the delamination. The excitation signal was a $50 \mathrm{kHz}, 5$ cycle sine wave modulated by Hanning window to match the experimental measurements.

A zero-volume delamination was incorporated into the model by overwriting the elements in a square region with the approximate dimensions of the delamination. New nodes, connected to one side of the plate, were generated in this region. A circular area was then defined within this square area and interpolated onto the Cartesian grid. A tie constraint is applied to the nodes that lie outside the circular area to form the edges of the delamination, as shown in Fig. 3a. 


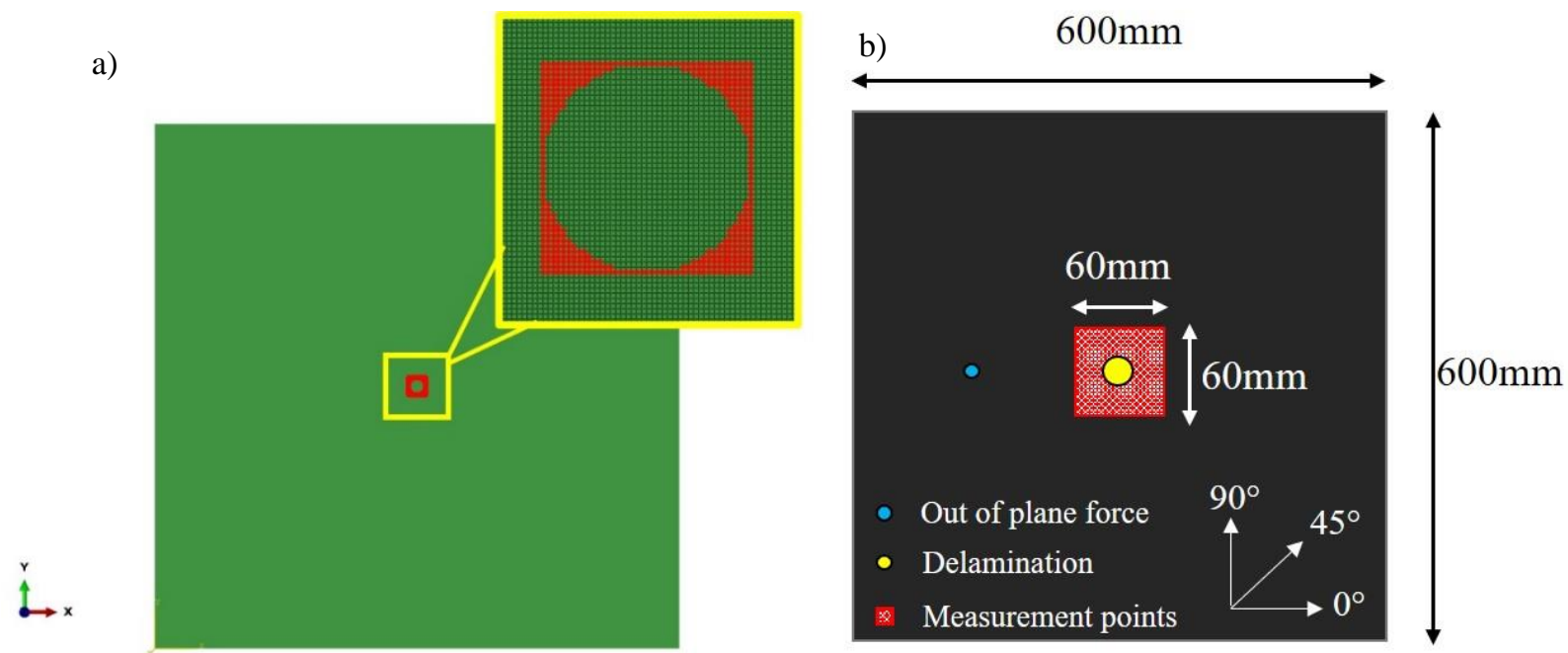

Figure 3: a) ABAQUS screenshot of the FE model; red dots indicate tied nodes forming the edges of the delamination;

b) schematic showing excitation and measurement locations for the FE model.

Both circular and ellipse shaped delaminations can be defined using this procedure. A $20 \mathrm{~mm}$ x $20 \mathrm{~mm}$ circular delamination was initially modelled and used as the standard case throughout this paper. A $20 \mathrm{~mm} \times 16 \mathrm{~mm}$ ellipse was also modelled to match the estimated dimensions from the C-scan. Finally, a $22 \mathrm{~mm}$ x $16 \mathrm{~mm}$ case was considered.

A $60 \mathrm{~mm}$ x $60 \mathrm{~mm}$ grid of measurement points, centered on the delamination, was defined on the surface of the plate in $1 \mathrm{~mm}$ steps. History outputs for the out-of-plane displacement were recorded for each measurement point. The recorded signals were further analyzed in MATLAB, where line and circle 'scans' could be selected from the full grid. The total energy of the signal at each measurement point was calculated, and the values were normalized using a reference value obtained from a baseline simulation containing no damage.

\section{INFLUENCE OF DELAMINATION SHAPE}

The effect of delamination shape on the interference on top of the delamination, and the scattered wave outside of the delamination was investigated for circular and ellipse shaped delaminations with various dimensions. In this paper three delamination cases were selected for comparison to the experimental results: a standard $20 \mathrm{~mm}$ x $20 \mathrm{~mm}$ circular delamination, a $20 \mathrm{~mm}$ x $16 \mathrm{~mm}$ delamination to match the estimated dimensions from the C-scan. Finally, a $22 \mathrm{~mm} \times 16$ mm delamination was selected to demonstrate how small changes in delamination size and shape affect scattering.

Figure 4a shows the measured energy over a $40 \mathrm{~mm}$ x $40 \mathrm{~mm}$ grid of measurement points. The incident wave is propagating from left to right. High energy is observed in a circular region on top of the delamination. Regions of high and low energy indicate that energy trapping is occurring in the top sub-laminate. A forward scattered wave is present to the right of the delamination, with two regions of low amplitude either side. In front of the delamination some interference between the incident and reflected wave can be observed, resulting in a faint crescent shape.

The 2D energy plots for each of the delamination cases considered in the FE simulations are shown in Fig. 4b/c/d. For each delamination case there is a region of high energy on top of the delamination, indicating wave trapping. A forward scattered component is present for each case, however the regions of low amplitude either side of the 'tail' are less pronounced for the FE results. The interference pattern on top of each of the simulated delamination cases is unique, indicating that small changes in the delamination shape and size can affect the reflections within the delamination. Visually, the pattern on top of the $20 \mathrm{~mm}$ x $16 \mathrm{~mm}$ delamination is the closest match to the measured pattern. Achieving a perfect match, however, would be unlikely as the edge effects of the real delamination have not been accounted for in the model. 

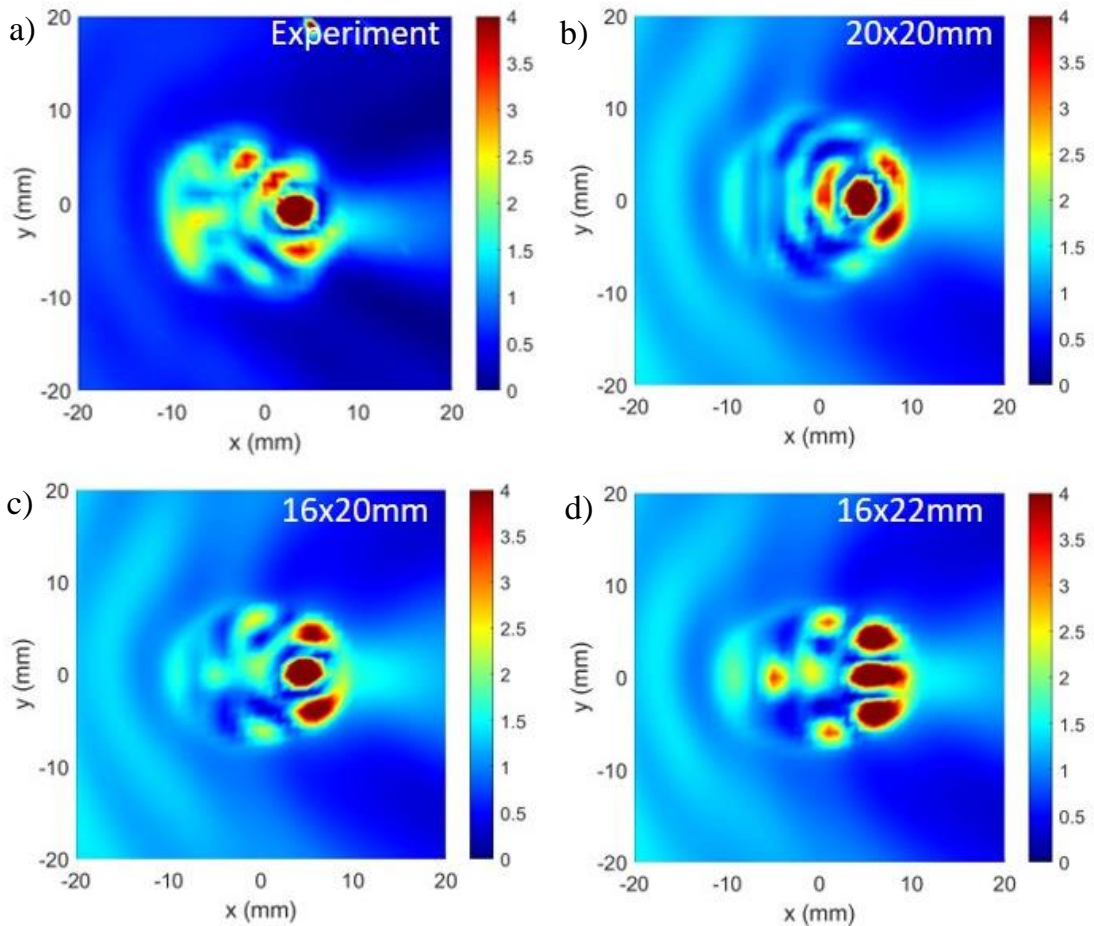

Figure 4: Signal energy at $50 \mathrm{kHz}$ for a) experimental measurement; b) FEA of $20 \mathrm{~mm}$ x $20 \mathrm{~mm}$ delamination;

c) FEA of $20 \mathrm{~mm} \times 16 \mathrm{~mm}$ delamination; d) FEA of $22 \mathrm{~mm} \times 16 \mathrm{~mm}$ delamination.

The measured and simulated normalized energy along a horizontal line of measurement points is presented in Fig. $5 \mathrm{a}$. Good agreement (within 5\%) was observed between the experiment and each of the FE delamination shapes for the incident wave $(-30 \mathrm{~mm}$ to $-12 \mathrm{~mm})$. The forward scattered wave beyond $+10 \mathrm{~mm}$ also shows good agreement for all cases. On top of the delamination region a significant increase in energy is observed, consistent with the 2D scans presented in Fig. 4. For the $20 \mathrm{~mm} \times 20 \mathrm{~mm}$ and $20 \mathrm{~mm} \times 16 \mathrm{~mm}$ delaminations, the location of the major peak at $+7 \mathrm{~mm}$ matches the experimental peak, however there is some variation in the magnitude of the energy at this location. The experimental energy trapping on top of the delamination is generally lower for the FE simulations, particularly towards the entrance of the delamination. The pattern of peaks inside the delamination is unique for each FE case.
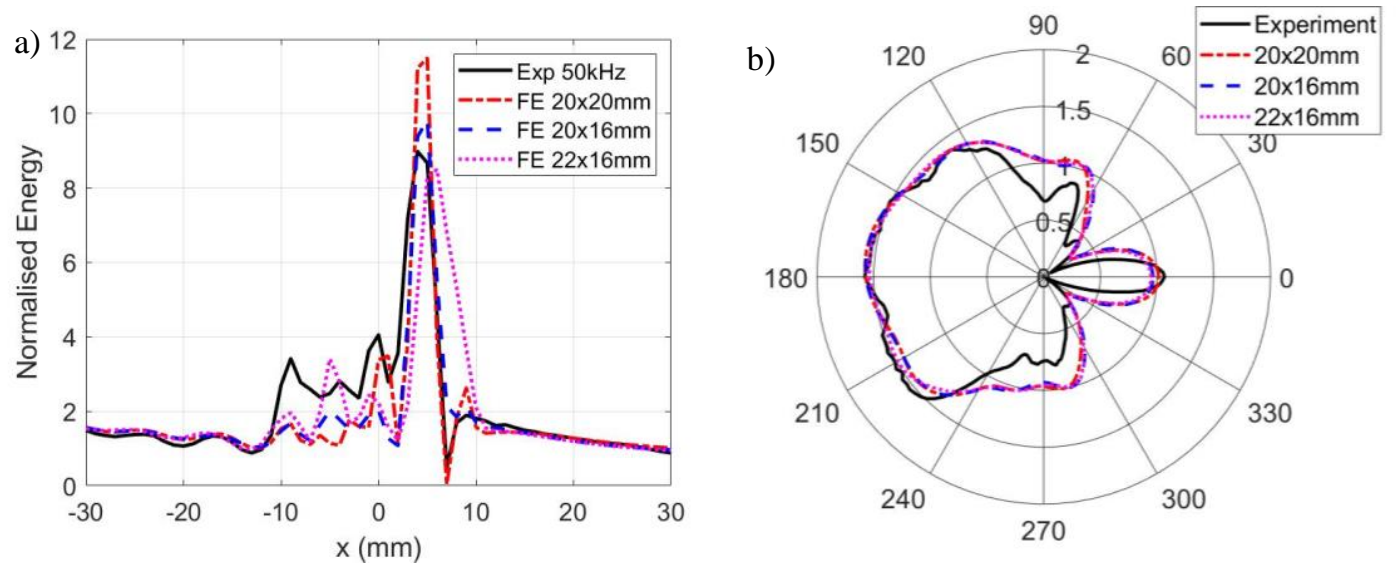

Figure 5: Comparison between measured and simulated energy for several delamination shapes along a) horizontal line passing through delamination center; b) circle of measurement points with radius $30 \mathrm{~mm}$, centered on the delamination. 
In contrast, the scattered energy on a $30 \mathrm{~mm}$ circle (in the undamaged part of the plate) shows limited variation with delamination shape, as demonstrated in Fig. 5b. Good agreement with the experiment is seen in the $0^{\circ}$ and $180^{\circ}$ directions. However, the reduction in $\mathrm{FE}$ amplitude at $30^{\circ}$ and $330^{\circ}$ is not as strong as observed in the measurements.

\section{INFLUENCE OF DELAMINATION DEPTH}

The depth of a $20 \mathrm{~mm}$ x $20 \mathrm{~mm}$ circular delamination was varied systematically between each of the ply layers in the laminate. Figure 6 shows the simulated energy field at each delamination ply depth. When the delamination is located between the first and second plies ( $0.2 \mathrm{~mm}$ depth, Fig. 6a) a region of low amplitude can be observed. This is in contrast to literature, which predicts large wave trapping amplitude for the thin sub-laminates due to the lower bending stiffness in a thinner structure. Wave trapping on top of the delamination is observed at $0.4 \mathrm{~mm}$ and $0.6 \mathrm{~mm}$ depth (Fig 6b/c). At the midplane of the plate (Fig. 6d) energy trapping on top of the delamination is limited, however a high energy forward scattered wave is present, with two distinct shadow regions of low amplitude either side of the high energy region. As the delamination depth is increased beyond the midplane (Fig 6e/f/g), limited amplitude increase is observed on top of the delamination as wave trapping is occurring in the lower sub-laminate on the opposite side of the plate to the monitoring points. At each delamination depth, the crescent shape in front of the defect indicates that interference between incident and reflected wave is occurring.

The angular variation of scattered energy with delamination depth, on a circle of measurement points $(\mathrm{r}=30 \mathrm{~mm})$ is presented in Fig. 7. The scattering patterns at symmetric delamination depths are identical, but indicate that delamination depth influences the scattered energy. This could be due to the different layup of the sub-laminates for different ply depths. For delaminations at a single ply layer depth (Fig. 7a) the energy drops in the $30^{\circ}$ direction. A forward scattered lobe in the $0^{\circ}$ direction is observed for both the ply $2-3$ case (Fig. 7b) and the ply $4-5$ case (Fig. 7d). The amplitude of the forward scattered lobe at the midplane is approximately $25 \%$ higher than observed for $0.4 \mathrm{~mm}$ delamination depth. This could be due to the symmetric ply layup of the sub-laminates for a mid-plane delamination. An asymmetric forward scattered lobe is observed for the ply 3-4 delamination, due to the asymmetry in the layup of the top sub-laminate for this case (Fig. 7c).
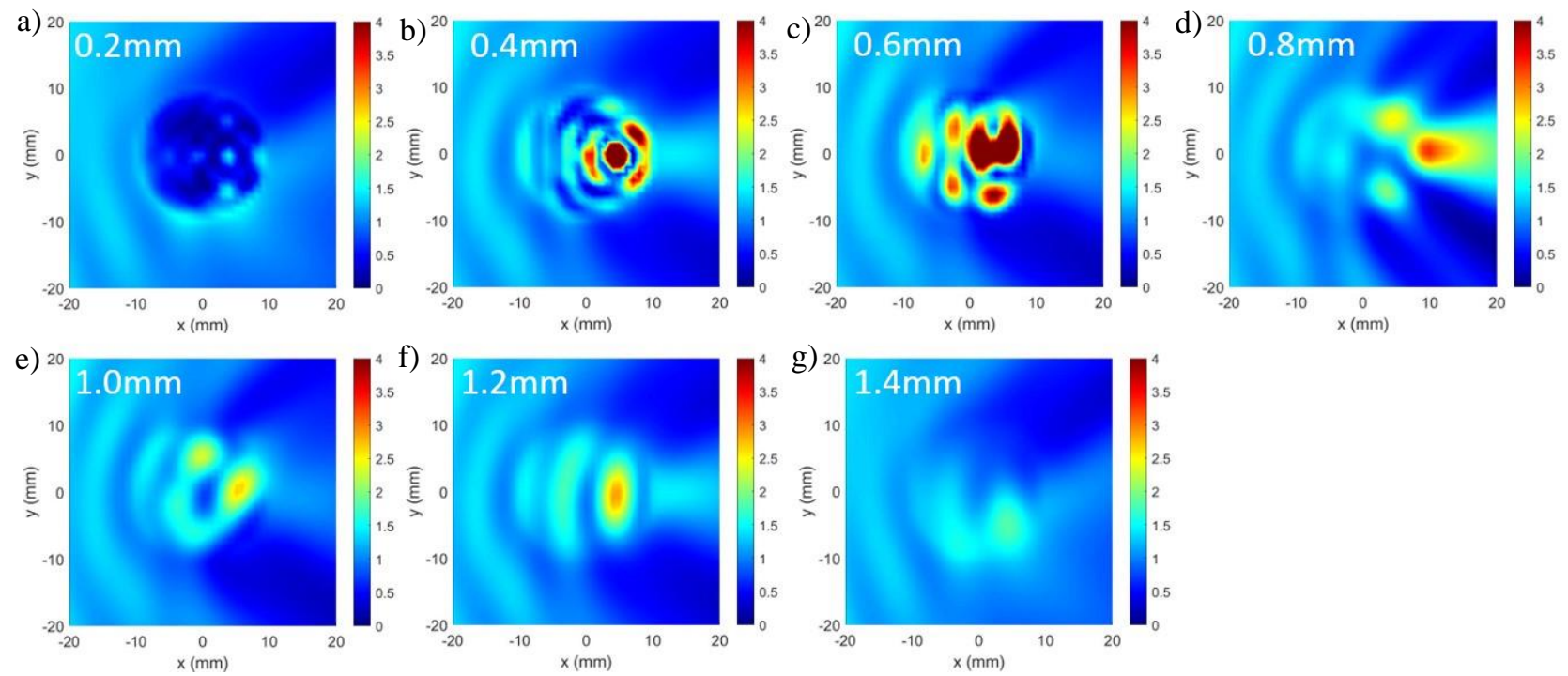

Figure 6: Normalized energy over $40 \mathrm{~mm} \mathrm{x} 40 \mathrm{~mm}$ grid at $50 \mathrm{kHz}$ for different delamination depths: a) $0.2 \mathrm{~mm}$ (ply 1-2);

b) $0.4 \mathrm{~mm}$ (ply 2-3); c) $0.6 \mathrm{~mm}$ (ply 3-4); d) $0.8 \mathrm{~mm}$ (ply 4-5) ; e) $1.0 \mathrm{~mm}$ (ply 5-6); f) $1.2 \mathrm{~mm}$ (ply 6-7);

g) $1.4 \mathrm{~mm}$ (ply 7-8). 

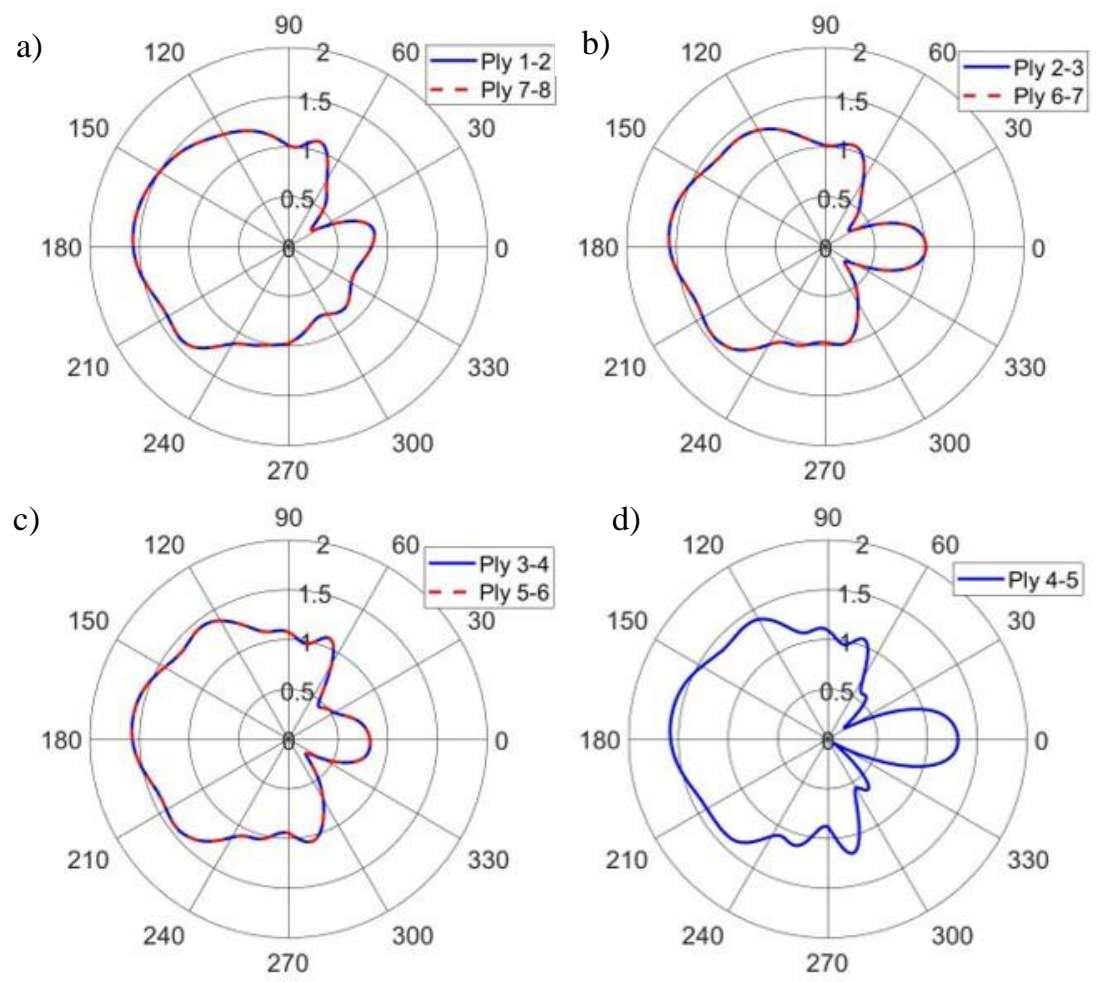

Figure 7: Normalized energy on 30mm circle of measurement points for symmetric delamination depths; a) 1 ply layer depth; b) 2 ply layer depth; c) 3 ply layer depth; d) midplane delamination.

\section{CONCLUSIONS}

Guided wave propagation and scattering in a quasi-isotropic laminate with an artificial insert delamination has been investigated through both noncontact laser measurements and finite element simulations. Good agreement was observed for the scattered energy outside of the delamination region. Reasonable agreement for the interference pattern on top of the delamination was observed. Small changes in delamination shape and size were demonstrated to have a significant effect on the wave trapping on top of the delamination, but showed only limited variation in scattered energy around the defect. In the simulations, the delamination depth was varied between each of the ply layers in the laminate. Wave trapping was generally observed for shallower defects, and the highest forward scattered energy was observed for the delamination at the mid-plane of the plate. Varying the delamination depth affects both the wave trapping on top of the delamination, and the scattering outside of it. Delaminations located at symmetric ply depths were shown to have identical scattering patterns in the undamaged part of the specimen. The sensitivity of guided waves for the detection of delaminations due to barely visible impact damage (BVID) in composite panels has been investigated.

\section{REFERENCES}

[1] Cantwell, W.J. and Morton, J., "Geometrical effects in the low velocity impact response of CFRP," Compos. Struct. 12, 39-59 (1989).

[2] Shyr, T. and Pan, Y., "Impact resistance and damage characteristics of composite laminates," Comp. Struct. 62, 193203 (2003).

[3] Wisnom, M., "The role of delamination in failure of fibre-reinforced composites," Philos. Trans. R. Soc. A., 370, 1850-1870, (2012).

[4] Prichard, J.C. and Hogg, P.J., "The role of impact damage in post-impacted compression testing," Compos. 21, 503$511(1990)$.

[5] Choi, N.S., Kinloch, A.J. and Williams, J.G., "Delamination fracture of multidirectional carbon-fiber/epoxy composites under mode I, mode II and mixed-mode I/II loading," J. Compos. Mater. 33, 73-100 (1999). 
[6] Endrizzi, M., Murat, B.I.S., Fromme, P. and Olivo, A., "Edge-illumination X-ray dark-field imaging for visualising defects in composite structures," Compos. Struct. 134, 895-899 (2015).

[7] Shoukroun, D., Massimi, L., Iacoviello, F., Endrizzi, M., Bate, D., Olivo, A. and Fromme, P., "Enhanced composite plate impact damage detection and characterisation using X-Ray refraction and scattering contrast combined with ultrasonic imaging," Compos. B 181, 107579 (2020).

[8] Smith, R., Nelson, L., Xie, N., Fraij, C. and Hallett, S., "Progress in 3D characterisation and modelling of monolithic carbon-fibre composites," Insight 57, 131-139 (2015).

[9] Guo, N. and Cawley, P., “The interaction of Lamb waves with delaminations in composite laminates," J. Acoust. Soc. Am. 94, 2240-2246 (1993).

[10] Pudipeddi, G., Ng, C. and Kotousov, A., "Mode conversion and scattering of Lamb waves at delaminations in composite laminates," J. Aerosp. Eng. 32, 04019067, (2019).

[11] Toyama, N. and Takatsubo, J., "Lamb wave method for quick inspection of impact-induced delamination in composite laminates," Compos. Sci. Technol. 64, 1293-1300 (2003).

[12] Tan, K.S., Guo, N. and Wond, B.S., "Experimental evaluation of delaminations in composite plates by the use of Lamb waves," Compos. Sci. Technol. 53, 77-84 (1995).

[13] Guy, P., Jayet, Y. and Goujon, L., "Guided wave interaction with complex delaminations. Application to damage detection in composite structures," Proc. SPIE 5047, 25-33 (2003).

[14] Ramadas, C., Balasubramaniam, K., Joshi, M. and Krishnamurthy, C.V., "Interaction of guided Lamb waves with an asymmetrically located delamination in a laminated composite plate," Smart Mater. Struct. 19, 065009 (2010).

[15] Hayashi, T. and Kawashima, K., "Multiple reflections of Lamb waves at a delamination,” Ultrasonics, 40, 193-197, (2002).

[16] Ng, C.T. and Veidt, M., "Scattering of the fundamental anti-symmetric Lamb wave at delaminations in composite laminates,” J. Acoust. Soc. Am. 129, 1288-1296 (2011).

[17] Gupta, S. and Rajagopal, P., "Effect of ply orientation and through thickness position of delamination on the reflection of fundamental symmetric S0 Lamb mode in GFRP composite plate structures," Ultrasonics 90, 109-119 (2018).

[18] Samaitis, V., Mažeika, L. and Rekuviene, R., "Assessment of the length and depth of delamination-type defects using ultrasonic guided waves," Appl. Sci. 10, 5236, (2020).

[19] Hayat, K. and Ha, S.K., "Low-velocity impact-induced delamination detection by use of the S0 guided wave mode in cross-ply composite plates: A numerical study," J. Mech. Sci. Technol. 28, 445-455 (2014).

[20] Murat, B.I.S., Khalili, P. and Fromme, P., "Scattering of guided waves at delaminations in composite plates," J. Acoust. Soc. Am. 139, 3044-3052 (2016).

[21] Chiu, W.K., Rose, L.R.F. and Nadarajah, N., "Scattering of the fundamental anti-symmetric Lamb wave by a midplane edge delamination in a fiber-composite laminate," Proc. Eng. 188, 317-324 (2017).

[22] Maio, L., Hervin, F. and Fromme, P., "Guided wave scattering analysis around a circular delamination in a quasiisotropic fiber-composite laminate," Proc. SPIE 11381, 11381Q (2020).

[23] Maio, L., Memmolo, V., Boccardi, S., Meola, C., Ricci, F., Boffa, N.D. and Monaco, E., "Ultrasonic and IR Thermographic Detection of a Defect in a Multilayered Composite Plate,” Proc. Eng. 167, 71-79 (2016).

[24] Maio, L., Ricci, F., Memmolo, V., Monaco, E. and Boffa, N.D., "Application of laser Doppler vibrometry for ultrasonic velocity assessment in a composite panel with defect," Comp. Struct. 184, 1030-1039 (2018). 